DOI: https://doi.org/10.24297/jap.v16i1.8243

\title{
Indentation Creep and Microstructure Properties of Sn-Ag Solder Alloys
}

\author{
B.A. Khalifa, R. Afify Ismail, A.M. Yassin \\ Physics department, Ain Shams University - Cairo Egypt \\ b.khalifa@sci.asu.edu.eg, Redaafify@sci.asu.edu.eg, amalyassin477@gmail.com
}

\begin{abstract}
The microstructure and micro-hardness of Sn-3.5wt.5\%Ag, Sn-3.5wt.\%Ag-0.27wt.\%Ti and Sn-3.5wt.\%Ag$0.27 \mathrm{wt} . \% \mathrm{Cd}$ treated at $75,100,125$ and $150^{\circ} \mathrm{C}$ were studied. The microstructure characteristics of the tested alloys had been investigated using optical microscope (OM), scanning electron microscope (SEM) and $x$-ray diffraction (XRD). The impression creep had been carried out using Vickers micro-hardness indenter under different loads (10, 50 and $100 \mathrm{gm}$ ). The stress exponent values were found to be varied from 3.2 to 8.4 . The energy activating the creep processes support dislocation climb as the rate controlling mechanism. The dislocation mobility was restricted due to the agglomerations of the Ag3Sn eutectic phase in the above three solders. Whereas; the presence of the twinning of $\beta-S n$ phase, and the dispersion of fine CdSn1.9 IMCs throughout Sn-3.5wt.\%Ag-0.27wt.\%Cd made strongly blockage of the dislocation motion.
\end{abstract}

\section{KEYWORDS}

Lead - free solders, Sn-Ag alloys, Microstructure, Twin boundaries, Impression creep, Ti and /or Cd additions

\section{INTRODUCTION}

A global movement away from using lead in the manufacture of industrial parts had led researchers to develop new lead-free solders [1-3]. Since the properties of the binary Pb-free solders cannot fully meet the requirements for applications in electronic and packaging; additional alloying elements were added to improve the performance of the lead-free solder alloys. Thus, ternary and even quaternary Pb-free solders have been developed [4-8]. Sn-Ag solders have received a great deal of attention as an alternative candidate for lead free solder materials. More studies have been carried on the microstructure and mechanical properties of SnAg solder alloys [9-15]. Several researches have addressed the possibility of gaining information of impression creep technique by the using indentation [16-25]. The majority of published work on the indentation and impression creep behavior of solder alloys has focused on the eutectic $\mathrm{Pb}-62.8 \% \mathrm{Sn}$ alloy [16, 26-29]. Recently Sn-Ag solder alloys have also been studied by indentation testing techniques [30, 31]. Eutectic Sn-3.5wt.\%Ag solder alloys have not enough studies, therefore, an attempts have been done. Shen Jun et. al [32] studied the effect of cooling rates on microstructure and micro-hardness of Sn-3 5\%Ag leadfree solder alloys. They found that the hardness of $\mathrm{Ag}_{3} \mathrm{Sn}$ eutectic phase formed in furnace-cooled specimen is about three or four times larger than that of the investigated solders solidified under different cooling conditions. The present work is devoted to study (i) the effect of aging temperatures on the eutectic SnAg specimens ranging from $75^{\circ} \mathrm{C}$ to $150^{\circ} \mathrm{C}$ and cooled in a switched off furnace to room temperature, (ii) the characterization of separate minor additions of $\mathrm{Ti}$ and/ or $\mathrm{Cd}$ on the indentation creep behavior of eutectic Sn3.5Ag lead-free solder alloys by measuring creep exponent $n$ and activation energies $Q$, (iii) comparison with the previous work is also given.

\section{INDENTATION CREEP ANALYSIS}

It is well known that the mechanical behavior of any metallic materials higher than 0.3 melting temperature (homologous temperatures) is expressed by the power-law applied on the steady state creep [34-36]. 


$$
\varepsilon=A \sigma^{n}
$$

where, $\varepsilon$ is the strain rate, $\sigma$ is the tensile applied stress at a constant temperature, A is constant and $n$ is the steady state stress exponent.

$$
n=\left[\frac{\partial \ln \varepsilon}{\partial \ln \sigma}\right]
$$

Mulhearn, Tabor, Geranmayeh and Abd-El-Rehim [37-39] have carried Vickers tests and estimated the stress exponent $n$ at the steady state creep using the following equation:

$$
-\left[n+\frac{1}{2}\right] \log H_{V}=\log t+B
$$

where, $H_{V}$ is Vickers hardness number, $t$ is the indentation dwell time and $B$ is constant.

To estimate the activation energy, the variation of minimum creep rate in terms of $1000 / T$ are drawn at different loads and alloys [40].

\section{EXPERIMENTAL WORK}

Solder alloys used in this work are Sn-3.5wt.5\%Ag, Sn-3.5wt.\%Ag-0.27wt.\%Ti and Sn-3.5wt.\%Ag-0.27wt.\%Cd, named S1, S2 and S3 respectively. They were prepared from high purity (99.98\%) Sn, Ag, Ti and Cd. All materials were melted in a graphite crucible using an electrical furnace. The alloy materials (ingots) are rolled into sheet form of $(1 \mathrm{~mm})$ thick. The sheet samples are homogenized at $100^{\circ} \mathrm{C}$ for 6 - hours then slowly cooled inside a switched off furnace to obtain samples containing the fully precipitated phases and free from any plastic strain accumulation during machining. After that, the sheets were treated at different temperatures ranging from $75^{\circ} \mathrm{C}$ to $150^{\circ} \mathrm{C}$ with an accuracy $\pm 1^{\circ} \mathrm{C}$ and then slowly cooled to room temperature; to study the effect of the aging temperatures on microstructure and micro hardness.

\subsection{Impression Creep Testes}

Hardness is measured on a polished surface of samples using Vickers Shimadzu micro-hardness tester to characterize the mechanical properties of the three alloys ( $\mathrm{S} 1, \mathrm{~S} 2$ and $\mathrm{S} 3$ ). Vickers micro-hardness $\left(H_{v}\right)$; which is considered as a quick, simple and non destructive procedure to extract information on the mechanical behavior of the material computed from the following expression [30, 40].

$$
H_{v}=1.8545 \frac{F}{d^{2}}
$$

where, $F$ is the applied load in $\mathrm{Kg}$ and $d$ is the average indentation diagonal length in $\mathrm{mm}$.

The micro-hardness values $\left(H_{v}\right)$ were measured using 10, 50 and $100 \mathrm{gm}$ loads for dwell times ranged from 5 $\mathrm{sec}$ to $65 \mathrm{sec}$. The pyramidal indenter made of diamond inclined angle of $136^{\circ}$ has been used. The distance between any two successive indentations should be at least $3 \mathrm{~mm}$ away from each other. The resulting indentations measured using the optical microscope and their average are calculated from the previous relation (equation no. 4). However, for data reliability, a repetitive number of indentations are important. This includes measurements of up to 10 indentation points for yielding the average hardness value. 


\subsection{Microstructure characterizations}

\subsection{1. $\mathrm{X}$ - ray studies}

The effect of aging temperatures on the alloy samples S3; which is considered the best alloy [15] are examined through the analysis of the obtained $x$-ray diffraction (XRD) using Philips X' Pert (MPD) goniometer PW3050/00 with graphite monochromatic using Cu-K $\alpha$ target and Ni filter operated at (40 K.V.) and (30 mA) to give radiation of wave length $(\lambda=0.15406 \mathrm{~nm})$. The $x$-ray diffractometer is employed for the identification of the phases formed in the alloys

\subsubsection{Morphological studies}

The original samples (S1, S2 and S3) are ground using Sic papers wet with water, then the samples are etched in a solution consisting of $10 \% \mathrm{ml} \mathrm{HCl}, 30 \% \mathrm{ml} \mathrm{HNO}_{3}$ and $95 \mathrm{ml} \mathrm{C}_{2} \mathrm{H}_{5} \mathrm{OH}$ for $30 \mathrm{sec}$ time and finally washed with distilled water. The microstructure characterizations are performed using both optical and scanning electron microscope (SEM) to observe the structure of the alloys

\section{RESLULTS AND DISCUSSIONS}

\subsection{Impression creep}

The variation of hardness values $\left(H_{v}\right)$ at different dwell times $(5-65 \mathrm{sec})$ under constant applied loads $(10,50$ and $100 \mathrm{gm}$ ) for the three solder alloys with aging temperatures (T) ranging from $75^{\circ} \mathrm{C}$ to $150^{\circ} \mathrm{C}$ is presented in Fig.1. It is clear that:- (i) the hardness values increased with increasing applied loads and decreased with the dwell times. (ii) under the same test conditions the hardness values of alloys show that $\mathrm{S} 1<\mathrm{S} 2<\mathrm{S} 3$. (iii) the hardness values are decreasing gradually with increasing temperature exhibiting a sudden increase at $125^{\circ} \mathrm{C}$. This variation with aging temperature may be attributed to the dissolution of $\mathrm{Ag}$ rich phase $\left(\mathrm{Ag}_{3} \mathrm{Sn}\right)$ intermetallic compound. Fig. 2 shows continuous decrease of $H_{v}$ against indentation time for S1, S2 and S3 aged at different temperatures and under different fixed applied loads. This is due to the increase of indentation area which is in agreement with M. Kamal et. al. [41]. Fig. $\mathbf{3}$ shows typical indentation creep curves (evaluated using Atkin model [42]) for the three solder alloys at different constant applied loads and annealing temperatures. It is important to observe that the shapes of all indentation creep curves of the present alloys are similar to conventional creep curves. The indentation creep curves exhibit two stages; normal primary creep stage, followed by a steady-state creep stage with constant creep rate (min. creep rate). It is not possible to record a third stage because the hardness test is actually a compression test, therefore necking and fracture of the specimen cannot occur. It can be seen that the creep strength of the tested alloys increases with the additions (Ti and/or Cd) traces. Among the investigated samples, S3 solder alloy exhibits the best creep resistance which is in agreement with the previous work [15]. Moreover, it can also be inferred from Fig. $\mathbf{3}$ that the creep rate decreases with increasing loads 


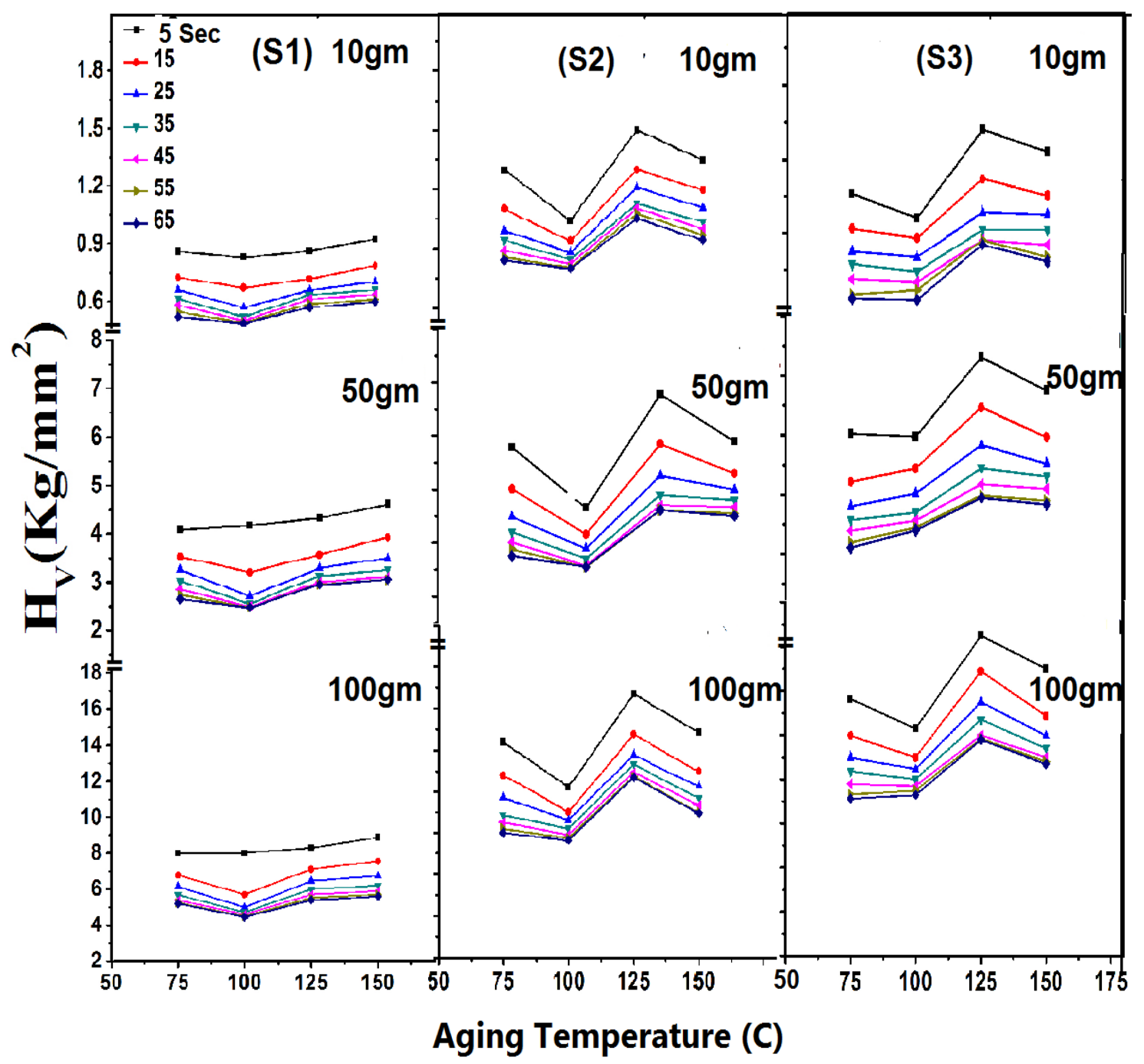

Fig. 1: The variations of hardness versus aging temperatures for the three solder alloys $(S 1, S 2, S 3)$ at different dwell times and under different constant applied loads 


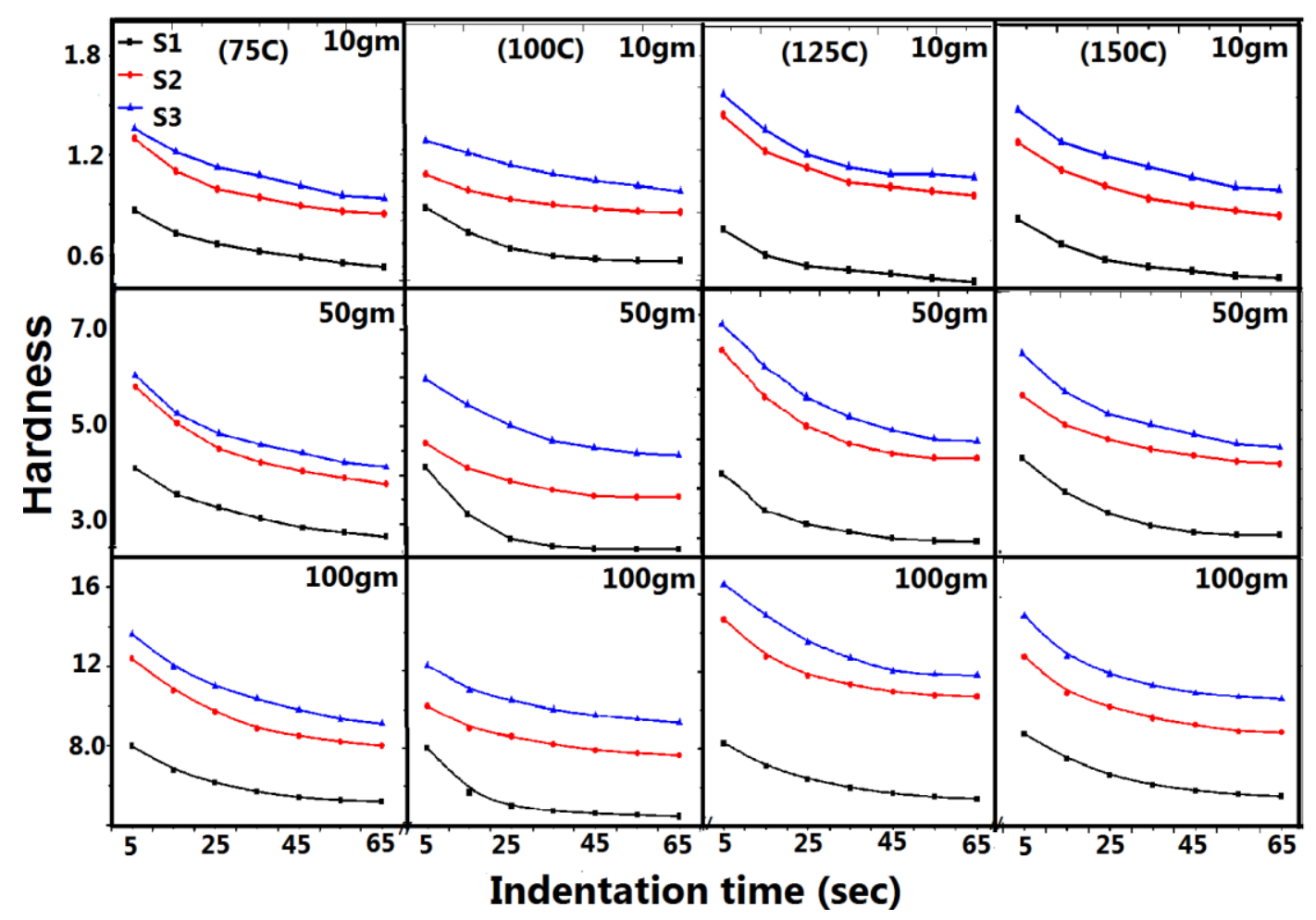

Fig. 2: Vickers Hardness against indentation time for S1, S2 and S3 solder alloys aged at different temperatures and under different constant applied loads.

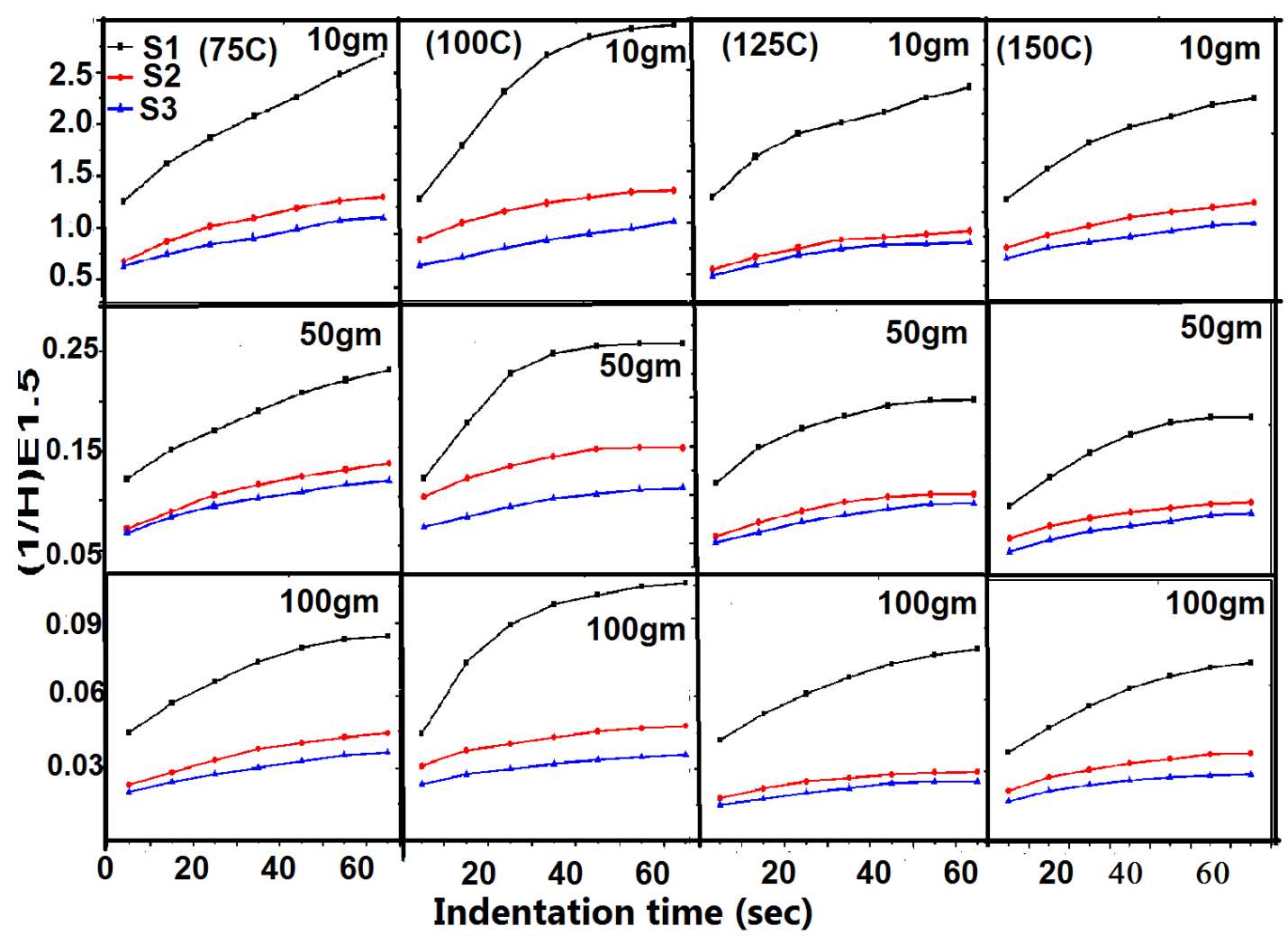

Fig. 3: Indentation creep curves for S1, S2 and S3 solder alloys aged at different temperatures and under different constant applied loads. 
To obtain the steady state creep exponents from Vickers-micro hardness, we flow Mulhearn \& Tabor expressions [37]. Linear fit plots between log $H_{v}$ against $\log t$ show straight lines with slopes $\left(n+\frac{1}{2}\right)^{-1}$ are shown in Fig. 4(a). The stress exponents calculated from the three aged alloys at different temperatures are tabulated in Table (1). It is found that $\mathrm{n}$ values increase with the additions ( $\mathrm{Ti}$ and /or $\mathrm{Cd}$ ), but decrease with increasing both loads and temperatures. The relations between the stress exponent $(n)$ and the aging temperatures (T) under different applied loads are given in Fig. $\mathbf{4}(\mathbf{b})$. The relationships between $\ln \varepsilon$ and $1000 / T$ are represented in Fig. 5. The average values of the activation energies $(\mathrm{Q})$ are found to be 38.0, 53.0 and 58.0; which were confirmed with our previous work $(37.4,52.3$ and $57.5 \mathrm{KJ} / \mathrm{mol})$ for S1, S2 and S3 respectively [15]. Table (2) summarizes the present and the previous values of the activation energies. Therefore, we can conclude that the indentation creep in the present study is controlled by climb of edge dislocation [15]

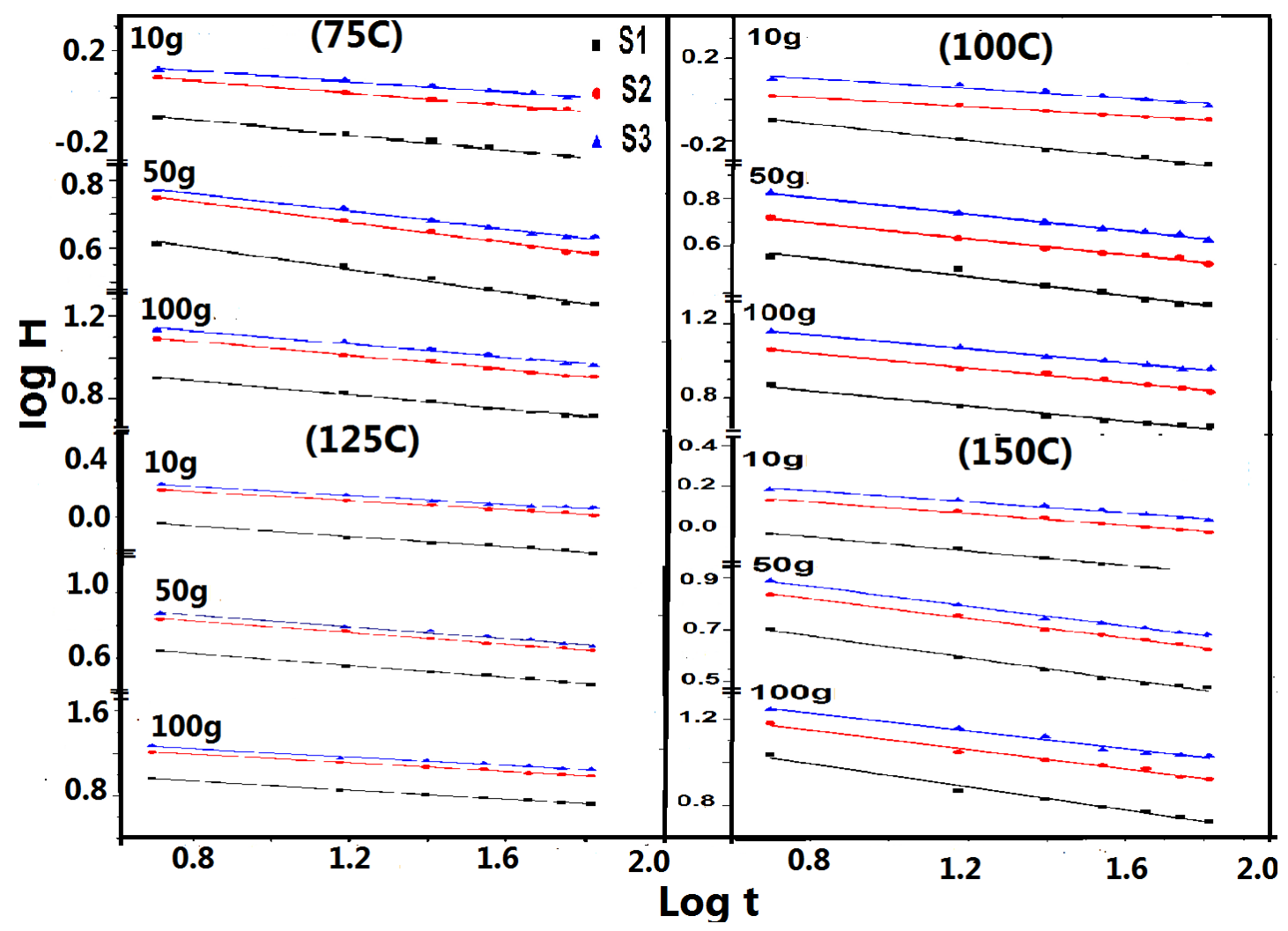

Fig. 4(a): Linear fit plots between $\log H_{v}$ against $\log t$ for the three aged alloys 


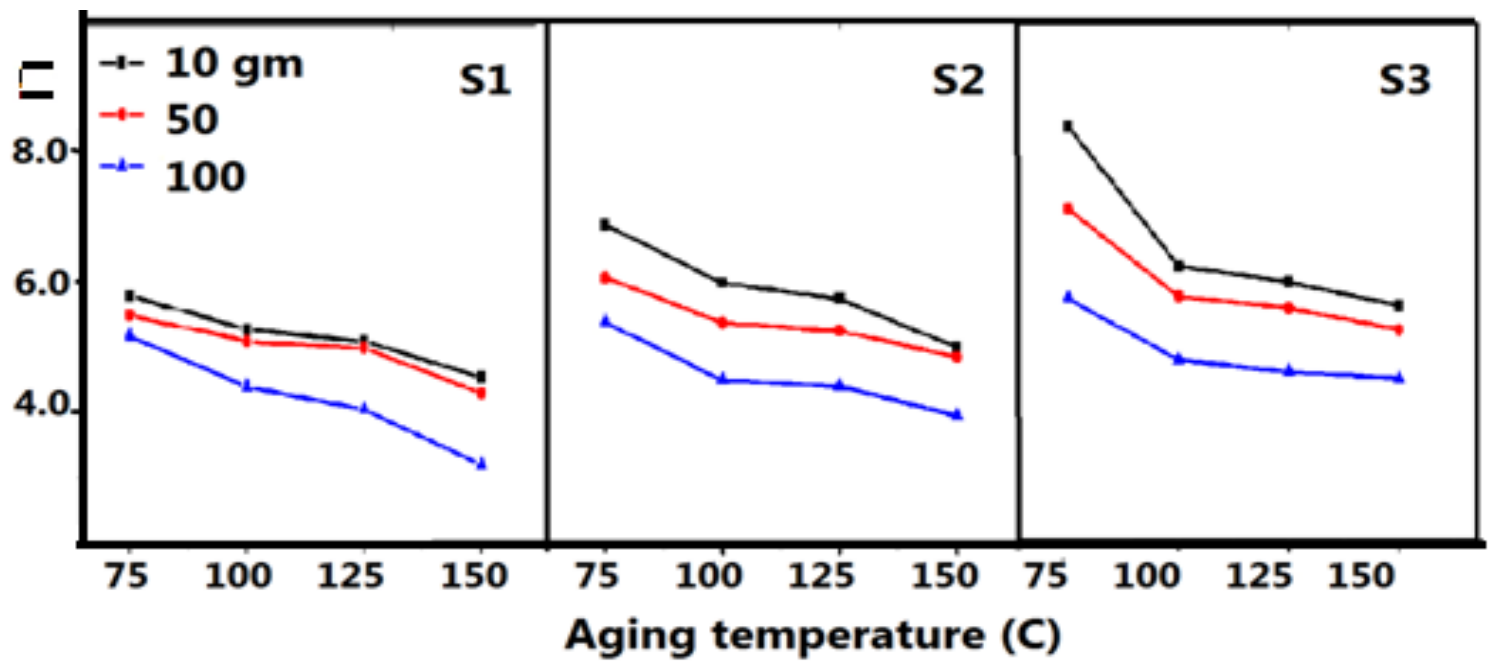

Fig. 4(b): Stress exponent (n) against aging temperatures (T) under different applied loads for S1, S2 and S3

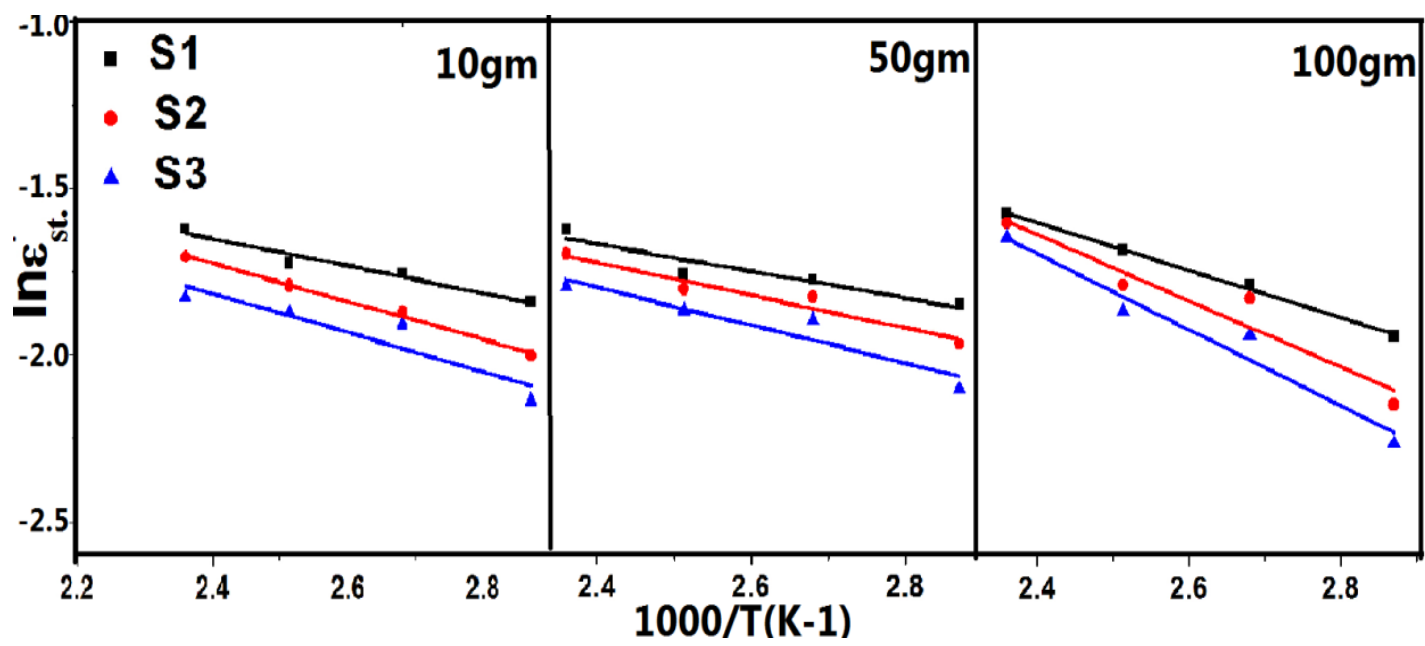

Fig. 5: The relationships between $\ln \varepsilon$ and $1000 / T$

Table (1): The stress exponents at different temperatures and loads

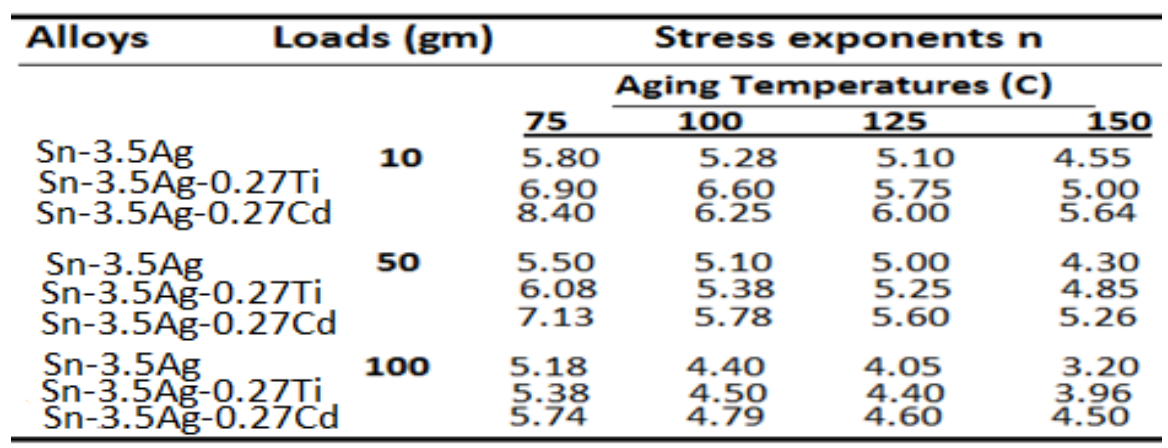


Table (2): The activation energies values

\begin{tabular}{lccc}
\hline Loads (gm) & \multicolumn{3}{c}{ Q Values (Kj/mol.) } \\
\hline & Sn-3.5Ag & Sn-3.5Ag-0.27Ti & Sn-3.5Ag-0.27Cd \\
\cline { 2 - 4 } $\mathbf{1 0}$ & 40.0 & 57.0 & 59.0 \\
$\mathbf{5 0}$ & 37.0 & 47.0 & 51.0 \\
$\mathbf{1 0 0}$ & 36.0 & 50.0 & 55.0 \\
Avg. & 38.0 & 53.0 & 58.0 \\
Previous work[15] & 37.4 & 52.3 & 57.5 \\
\hline
\end{tabular}

\subsection{XRD analysis}

The XRD analysis was employed in order to identify the type of the precipitated phases. Fig.6 (a) shows the XRD profile of S3 alloy aged at $75,100,125$ and $150^{\circ} \mathrm{C}$. The patterns show peaks due to $\beta$-Sn matrix, $\mathrm{Ag}_{3} \mathrm{Sn}$ and CdSn1.9 IMCs.

(a)

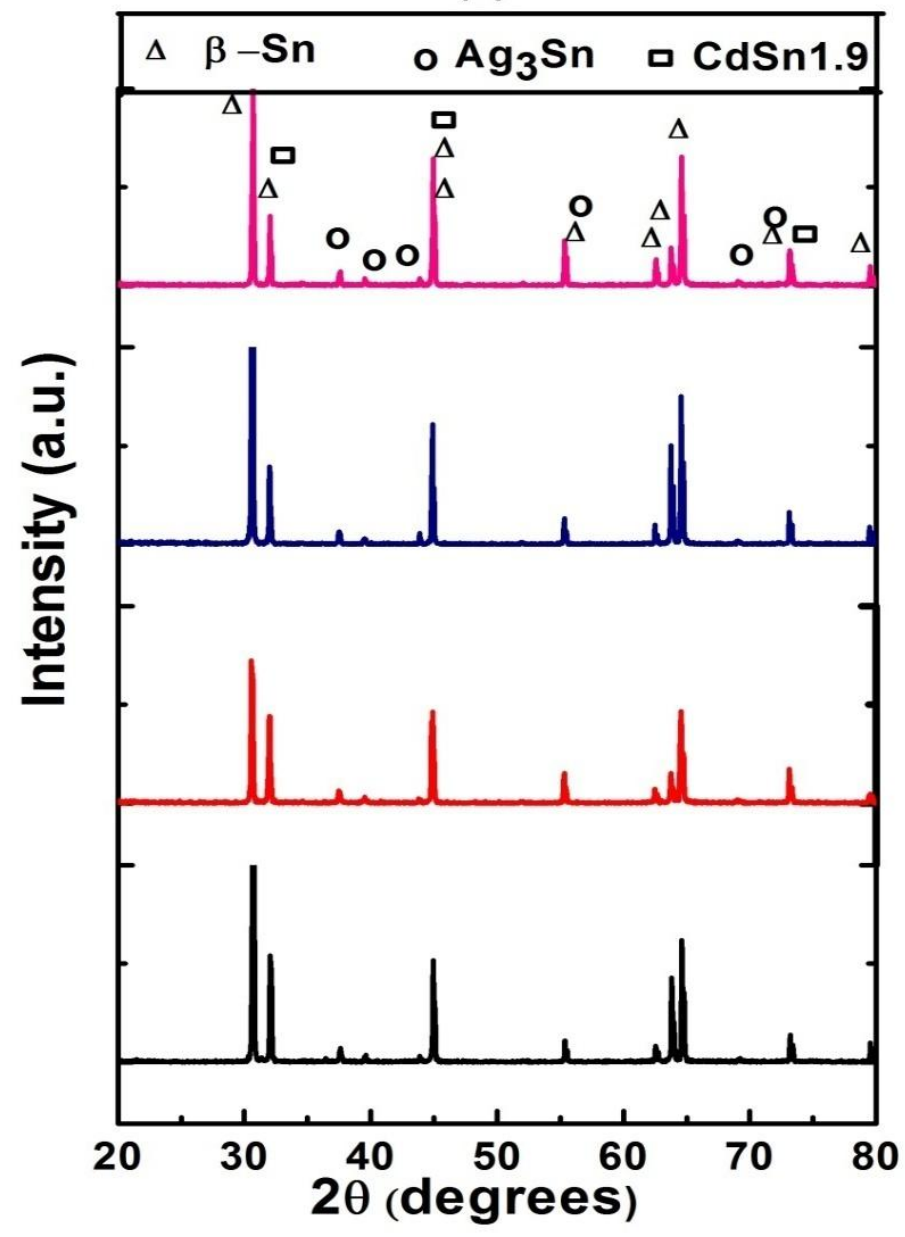

Fig. $6(\mathrm{a})$ : shows the XRD profile of S3 alloy aged at $75,100,125$ and $150^{\circ} \mathrm{C}$. 


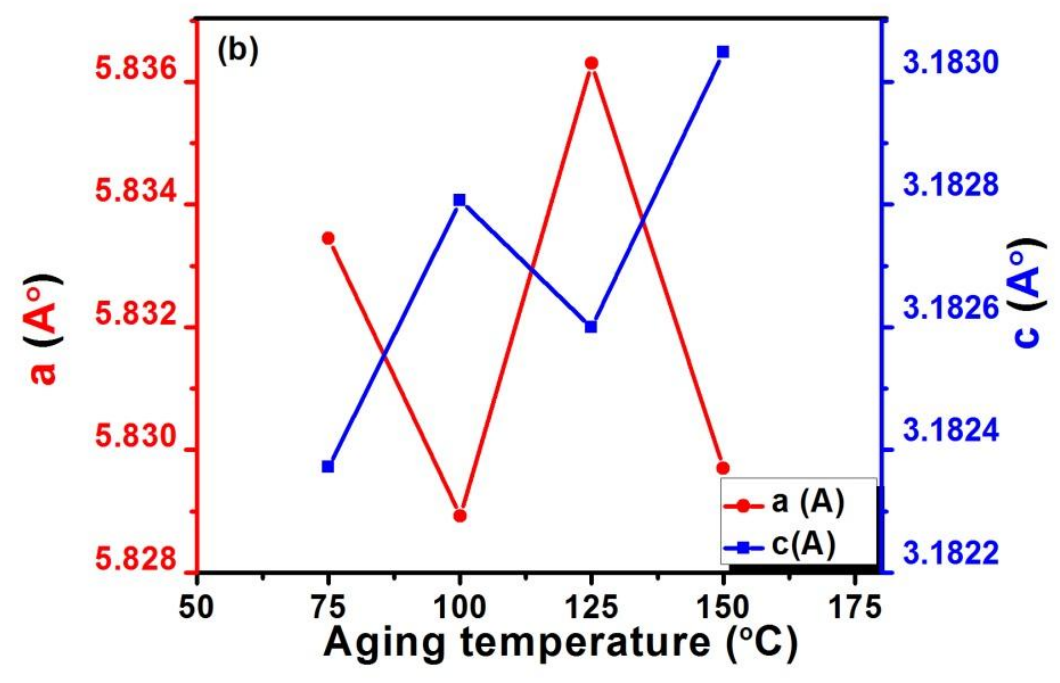

Fig. 6(b): The $x$-ray lattice parameters $(a, c)$ as a function of aging temperatures

The $x$-ray lattice parameters $(a, c)$ as a function of aging temperatures are represented in Fig. $\mathbf{6}(\mathbf{b})$. It was found that a \& c are in reverse direction. Fig. $\mathbf{6}(\mathbf{c}, \mathbf{d})$ represents the relations between the intensity of some crystallographic planes [(200) \& (400)], [(211) \& (312)] and aging temperatures . Fig. 6(e) shows the variation of full width at half maximum intensity $\Delta 2 \theta$ for the planes (200) \& (220). The apparent crystallite size values (L) for S3 sample normal to some crystallographic planes [(200), (101), (211), (400) \& (321)] after resolution of $K \alpha_{1,}$ $\mathrm{Ka}_{2}$ intensities were calculated according to Scherer equation [15].

$$
L=K \lambda / \beta \cos \theta .
$$

where, $\mathrm{K}$ is the Scherer parameter equal to $0.94, \beta$ is the HMFW calculated for the above five planes, $\lambda$ is the $x$-ray wave length of $0.1541 \mathrm{~nm}, 2 \theta$ is the Bragg angel. It was noted that the variation in all $x$-ray parameters followed the same behavior of the indentation creep behavior; which show an anomalous behavior at the same temperature $\left(125^{\circ} \mathrm{C}\right)$ due to the presence of $\mathrm{Ag}_{3} \mathrm{Sn}$ (IMC).

The strain values $(\varepsilon)$ and the dislocation density $(\rho)[39,43]$, are calculated from the following relations.

$$
\begin{aligned}
& B=\lambda / L \cos \theta-\varepsilon \tan \theta . \\
& \rho=1 / L^{2} \ldots \ldots \ldots \ldots \ldots \ldots \ldots \ldots \ldots \ldots \ldots \ldots \ldots
\end{aligned}
$$



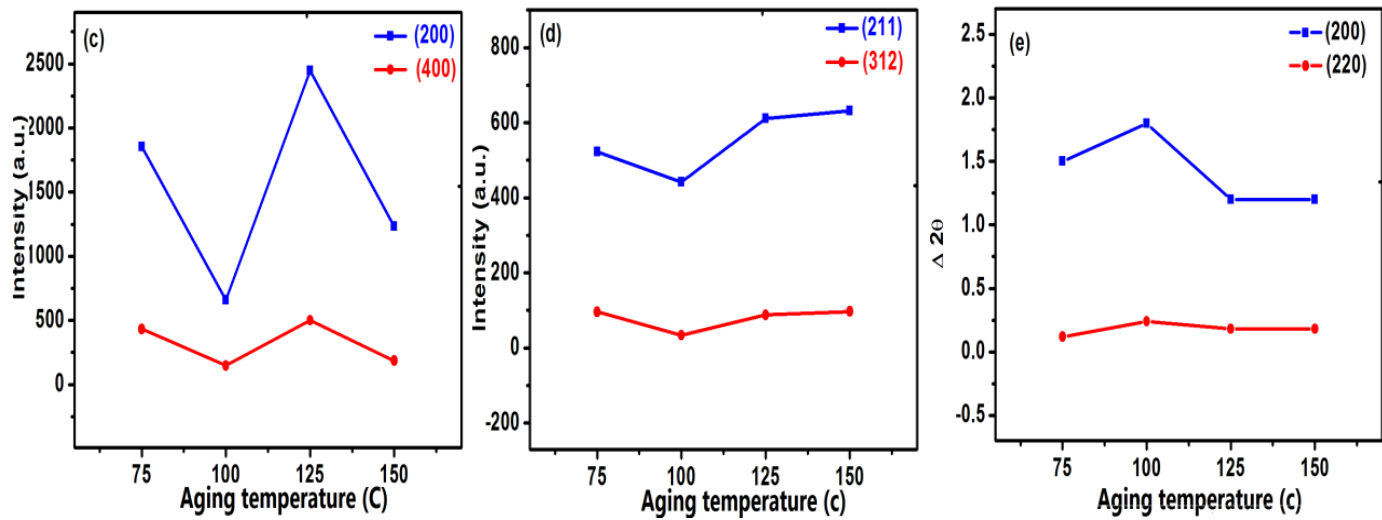

Fig. $6(c, d, e)$ : Shows the relations between the intensities of some crystallographic plans and the variation of full width at half maximum intensity $\Delta \mathbf{2 \theta}$ against the aging temperatures
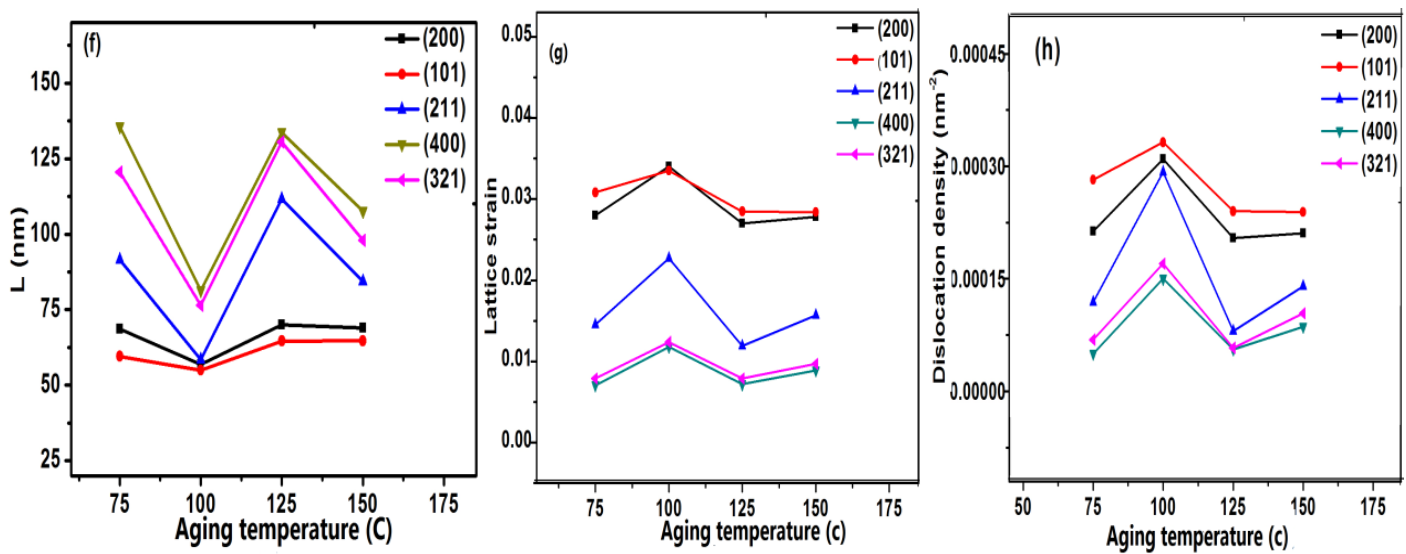

Fig. $6(f, g, h)$ : Represents the variations of the crystallite sizes, lattice strains and dislocation densities as a function of the aging temperatures

The crystallite sizes, lattice strains and dislocation densities for some crystallographic planes are illustrated in Fig. 6(f-h) and their values are tabulated in Table (3). It is found that the crystallite sizes are in reverse to the strains $(\varepsilon)$ and dislocation densities $(\rho)$. All the $x$-ray parameters confirm the hardness measurements.

Table (3): The crystallite size, lattice strain and dislocation density for some crystallographic planes as a function of aging temperatures

\begin{tabular}{|c|c|c|c|c|c|c|c|c|c|c|c|c|}
\hline \multirow{3}{*}{ Plane } & \multicolumn{12}{|c|}{ Aging Temper ature $\left({ }^{\circ} \mathrm{C}\right)$} \\
\hline & \multicolumn{3}{|c|}{75} & \multicolumn{3}{|c|}{100} & \multicolumn{3}{|c|}{125} & \multicolumn{3}{|c|}{150} \\
\hline & $\mathrm{L}(\mathrm{nm})$ & $\varepsilon$ & $\mathrm{p} x \mathrm{ll} 0^{-4}$ & $\mathrm{~L}(\mathrm{~nm})$ & $\varepsilon$ & $0 \times 10^{-4}$ & $\mathrm{~L}(\mathrm{~nm})$ & $\varepsilon$ & $\mathrm{pxl} 0^{-4}$ & $\mathrm{~L}(\mathrm{~nm})$ & $\varepsilon$ & $\mathrm{p} \times 10^{-4}$ \\
\hline$(200)$ & 68.5 & 0.028 & 2.13 & 56.8 & 0.034 & 3.10 & 70.0 & 0.027 & 2.040 & 68.90 & 0.028 & 2.11 \\
\hline (101) & 59.6 & 0.031 & 2.82 & 54.9 & 0.034 & 3.32 & 64.6 & 0.029 & 2.400 & 64.70 & 0.028 & 2.39 \\
\hline (211) & 91.5 & 0.015 & 1.19 & 58.5 & 0.023 & 2.92 & 111.6 & 0.012 & 0.800 & 84.30 & 0.016 & 1.40 \\
\hline$(400)$ & 135.7 & 0.007 & 0.54 & 81.4 & 0.012 & 1.50 & 133.7 & 0.007 & 0.560 & 107.8 & 0.009 & 0.86 \\
\hline (321) & 120.6 & 0.008 & 0.68 & 76.4 & 0.012 & 1.70 & 130.6 & 0.008 & 0.058 & 97.93 & 0.010 & 1.04 \\
\hline Ave. (L & L) 95.0 & & & 65.0 & & & 102.0 & & & 84.0 & & \\
\hline
\end{tabular}




\subsection{Morphological analysis}

The microstructure of the Sn-3.5wt.\%Ag-0.27wt.\%Cd alloy, is shown in Fig. 7. Optical micrograph (OM) [fig. 7(a)] shows dark and bright areas, beside a twinning character distributed throughout the whole sample. The twins are marked as an example in the figure; which have straight and parallel sides. The spread of the twinning of $\beta-\mathrm{Sn}$ inside $\mathrm{Ag}_{3} \mathrm{Sn}$ eutectic phase makes the dislocation mobility difficult; which explain the high creep resistance of the solder alloy (Sn-3.5wt.\%Ag-0.27wt.\%Cd). Scanning electron microscope (SEM) micrograph is shown in Fig. 7(b). SEM micrograph shows relatively large $\beta$-Sn regions, surrounded by Ag3Sn eutectic structure. The presence of the twinning of Sn-rich matrix and small amount of fine dark black CdSn1.9 (IMCs.) dispersed throughout the sample, besides some eutectic agglomeration (due to aging/slowly cooling) act as reinforcing factors causing effective blockage of dislocation mobility and strongly improves the micro hardness of the Sn-3.5wt.\%Ag solder.
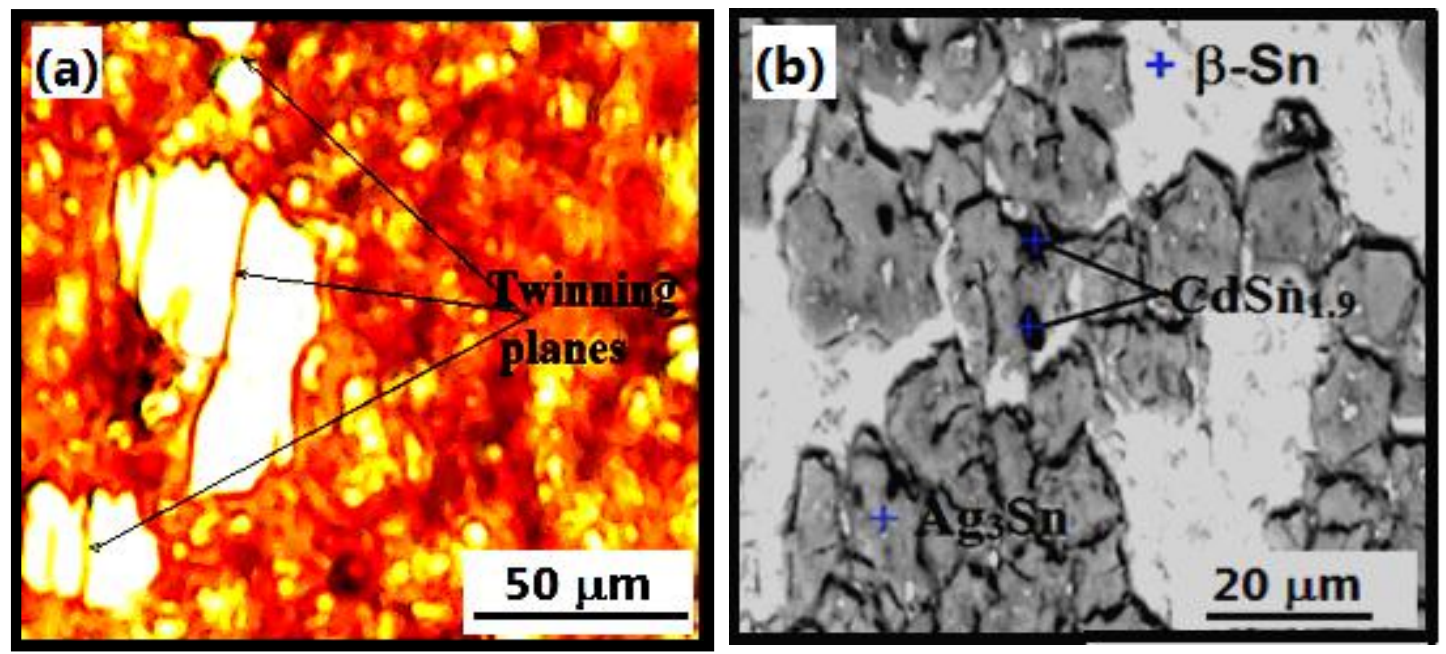

Fig. 7(a, b): Optical and Scanning electron micrographs

\section{CONCLUSIONS}

The effect of annealing temperatures $\left(75,100,125,150^{\circ} \mathrm{C}\right)$ for $120 \mathrm{~min}$. on structure and mechanical properties of S1, S2 and S3 solder alloys prepared by conventional casting method, then subjected to cold rolling process. The results showed that:

1) Vickers hardness number of this alloy decreased continuously with increasing annealing temperature and increased with increasing applied loads except at $125^{\circ} \mathrm{C}$ (an abrupt increase explained by the dissolution of Ag3Sn eutectic phase).

2) The hardness of Sn-3.5wt.\%Ag alloy is controlled by a tough eutectic Ag3Sn and soft $\beta$-Sn phase.

3) The stress exponents are increased with the addition ( $\mathrm{Ti}$ and/or $\mathrm{Cd}$ ) while, decreased by increasing both loads and annealing temperatures.

4) The stress exponent values were found to be varied from 3.2 to $5.8,3.96$ to 6.9 and 4.5 to the restriction of dislocation motion caused due to the presence of 8.4 for S1, S2 and S3 respectively.

5) The activation energies $Q$ for indentation creep of the tested solder alloys were varied between 38.0 and $58.0 \mathrm{KJ} / \mathrm{mol}$. which were in good agreement with those obtained from conventional uni-axial creep tests in our previous work [15] 
6) Experimental results indicate that the creep of the alloys under both conditions of $\mathrm{n}(3.2-8.4)$ and $\mathrm{Q}(38.0$ - $58.0 \mathrm{KJ} / \mathrm{mol}$.), is controlled by dislocation climb.

7) The crystallite size (L) of the $\beta$-Sn matrix was decreased with increasing annealing temperature except at $125^{\circ} \mathrm{C}$ (an abrupt increase), while the lattice strain $(\varepsilon)$ induced through the cold rolling process was decreased. $L$ and $\varepsilon$ parameters confirm the mechanical behavior.

8) The Sn-3.5wt.\%Ag- $0.27 \mathrm{wt} . \% \mathrm{Cd}$ solder alloy exhibited the best creep resistance due to the presence of the twinning of $\beta-S n$ phase, the agglomerations of the Ag3Sn eutectic phase and the fine dispersion of CdSn1.9 (IMCs.). Those three reasons made dislocation mobility blockage.

\section{REFERENCES}

[1] A.K. Gain, and Y.C. Chan, "Growth mechanism of inter-metallic compounds and damping properties of SnAg-Cu-1wt\% nano-ZrO2 composite solders", Micro electron. Reliab., 54, (2014) 945-966

[2] A.F. Abd El-Rehim, and H.Y. Zahran, "Effect of aging treatment on microstructure and creep behavior of Sn-Ag and Sn-Ag-Bi solder alloys", Mater. Sci. Technol., 30, (2014) 434-438

[3] W. R. Osórioa, J. E. Spinelli, C. R. M. Afonsob, L. C. Peixotoc and A. Garciac, "Microstructure, corrosion behaviour and microhardness of a directionally solidified Sn-Cu solder alloy", Electrochim. Acta, 56, (2011) 8891-8899

[4] A. Abtew, G. Selvaduray, "Lead-free solders in microelectronics", Mater, Sci. Eng. Rep. 27, 5, (2000) 95-141

[5] I.E. Anderson, J.C. Foley, B.A. Cook, J. Harringa, R.L. Terpstra, O. Unal, "Alloying effects in near-eutectic SnAg-Cu solder alloys for improved microstrctural stability", J. electron. Mater. 30, 9, (2001) 1050-105

[6] M. McCormack, S. Jin, G.W. Kammlott, H.S. Chen, "New Pb-free solder alloy with superior mechanical properties", Appl. Phys. Lett.63, 1 (1993) 15-17

[7] A.Z. Miric and A. Grusd, "Lead-free alloys", Soldering Surf. Mount Technol. 10, 1, (1998) 19-25

[8] ICdA International Cadmium Association.[http://www.cadmium.org/cadmium-applications/cadmium-inalloys]

[9] A.M. Yassin, E. Gomaa, "The of microstructure and creep properties of Cu-doped Sn-4wt\%Ag and Sn9wt\%Zn lead free solders with annealing temperature", Physics Journal, 1, (2015) 163- 172

[10] M.L. Hung, and L. Wang, "Effects of $\mathrm{Cu}, \mathrm{Bi}$ and In on microstructure \& tensile properties of Sn-Ag-x(Cu, Bi, In) solders", Metall. Matter. Trans. A 36 (2005) 1439-1446

[11] L.P. Lehman, S.N. Athavale, T.Z. Fullem, A.C. Gianmis, R.K. Kinyanjui, M. Lowenstein, K. Mather, R. Patel, D. Raw, J. Wang, X. Xing, L. Zavalij, P. Borgesen and E. J. Cotts, "Growth of Sn and intermetallic compounds in Sn-Ag-Cu solder", J. Electron. Mat's, 33, 12, (2004) 1429-1439

[12] S.K. Kang, W.K. Choi, D.Y. Shih, D.W. Henderson, T. Gosselin, A. Sarkhel, C. Goldsmith, K.J. Puttlitz, "Ag3Sn plate formation in the solidification of near ternary eutectic Sn-Ag-Cu alloys", J. the minerals, metals and materials (JOM) 55, (2003) 61- 65

[13] K.S. Kim, S.H. Huh, K. Suganuma, "Effects of forth alloying additive on microstructures and tensile properties of Sn-Ag-Cu alloy and joints with Cu", Micro electron. Reliab. 43, (2003) 259-267 
[14] M. Wang, J. Wang, H. Feng, W. Ke, "Effect of $\mathrm{Ag}_{3} \mathrm{Sn}$ inetermetallic compounds on corrosion of Sn-3.0Ag0.5Cu solder under high temperature \& high humidity condition", Corros, Sci. 63, (2012) 20-28

[15] B.A. Khalifa, R. Afify Ismail, A. Yassin, "Structure Analysis, Enhancement of Creep Resistance and Thermal Properties of Eutectic Sn-Ag Lead-Free Solder Alloy by Ti and Cd Additions", Journal of advances of Physics, 13, 8, (2017) 5059-5099

[16] M. Fujiwara and M. Otsuka, Mater. Sci. Eng. A319-A321, (2001) 929

[17] R. Mahmudi, R. Roumina, and B. Raeisinia, Mater. Sci.Eng. A 382, (2004) 15

[18] T.R.G. Kutty, T. Jarvis, and C. Ganguly, J. Nucl. Mater.246, (1997) 189

[19] R. Roumina, B. Raeisinia, and R. Mahmudi, Scripta Mater.51, (2004) 497

[20] T.R.G. Kutty, C. Ganguly, and D.H. Sastry, Scripta Mater.34, (1996) 1833

[21] S.N.G. Chu and J.C.M. Li, Mater. Sci. Eng. 39, (1979) 1

[22] R. Mahmudi, A.R. Geranmayeh, B. Zahiri, and M.H. Marvasti, Mater. Sci. Mater. Electron. 21, (2010) 58

[23] R. Mahmudi and M. Eslami, J. Electron. Mater. 39, (2010) 2495

[24] A.R. Geranmayeh, G. Nayyeri, and R. Mahmudi, Mater. Sci. Eng. A 547, (2012) 110

[25] F. Yang and J.C.M. Li, Mater. Sci. Eng. Rep. 74, (2013) 233

[26] F. Yang and J.C.M. Li, Mater. Sci. Eng, A201, (1995) 40

[27] A. Juhasz, P. Tasnadi, P. Szasvari, and I. Kovacs, J. Mater. Sci. 21, (1986) 3278

[28] M.J. Mayo and W.D. Nix, Acta Metall. 36, (1988) 2183

[29] K.L. Murty, Mater. Sci. Eng. A14, (1974) 169

[30] S. Devaki Rani and G.S. Murthy, Mater. Sci. Technol. 20, (2004) 403

[31]I. Dutta, C. Park, and S. Choi, Mater. Sci. Eng. A379, (2004) 401

[32] Shen Jun, LIU Yong-Chang, Han Ya-Jing, Gao Hou-Xiu, We1 Chen Y, A Ng Yu-Qin, Trans. Nonferrous Met. Soc. China, 16, (2006) 59-64

[33] G. Cseh, N.Q. Chinh. P. Tasnadi, and A. Juhasz, J. Mater.Sci. 32, (1997) 5107

[34] P.M. Sargent and M.F. Ashby, Mater. Sci. Technol. 8, (1992) 594

[35] B.N. Lucas and W.C. Oliver, Metall. Mater. Trans. A 30A, (1999) 601

[36] T.G. Langdon, Mater. Sci. Eng. A283, (2000) 266

[37] T.O. Mulhearn and D. Tabor, J. Inst. Met. 89, (1960) 7 
[38] A.R. Geranmayehi and R. Mahmudi, "Room-Temperature Indentation Creep of Lead-Free Sn-5\%Sb Solder Alloy " Journal of Electronic Materials, 34, 7, (2005) 1002-1009

[39] S.M. Abdelaziz, H.Y. Zahran, A.F. Abd El-Rehim, " Microstructure and Mechaniical Properties of Tin Bismuth Solder Alloy Reinforced by Antimony Oxide Nanoparticles" .International Journal of Advances in Engineering \& Technology, 10, 1, (2017) 73-83

[40] A.F.Abd El-Rehim, and H.Y. Zahran, "Investigation of microstructure and mechanical properties of Sn-xCu solder alloys" Journal of alloys and compounds 695 (2017) 3666-3673

[41] M. Kamal1, El Said Gouda, and L. K. Marei, "Effect of Bi-content on hardness and micro-creep behavior of Sn-3.5Ag rapidly solidified alloy", Cryst. Res. Technol. 44, 12, (2009) $1308-1312$

[42] A.G. Atkins, "The Science of Hardness Testing and its Research Applications", ASM, Metal Park, OH, (1971) 223

[43]E. F. Abo - Zeid, and A. Gaber, "Mechanical properties and precipitation behavior as a function of heat treatment of Al-4.4Cu-1.5Mg-0.6Mn-0.25Si (wt.\%) alloy, Int. J. Metall. \& Mater. Sci. Eng., 2, (2012) 11-20 